\title{
A AYAHUASCA E O TRATAMENTO DA DEPENDÊNCIA*
}

Marcelo S. Mercante

\section{Introdução}

Este texto é resultado da coleta de dados feita para o projeto de pesquisa de pós-doutorado que teve por objetivo o estudo de três comunidades no Brasil e uma no Peru que utilizam a ayahuasca para tratar dependência. ${ }^{1}$ Vale dizer que, inicialmente, havia sido feita a opção de colocar no título deste projeto as categorias "dependência química" e "alcoolismo". Contudo, percebi ser esta uma redundância, pois o alcoolismo é uma modalidade de dependência química. ${ }^{2}$ Além disso, outras modalidades de dependência que não a química estavam sendo tratadas nos centros visitados. ${ }^{3}$

A bebida psicoativa conhecida com vários nomes, entre eles ayahuasca, tem como princípios ativos mais importantes as betacarbolinas, oriundas do cipó Banisteriopsiscaapi, e a dimetiltriptamina (DMT), oriunda das folhas de Psychotriaviridis. Ambas as substâncias atuam no nível de serotonina no cérebro (McKenna 2004, Winkelman 1996).

A partir de 1930, o uso da ayahuasca influenciou o surgimento de três sistemas religiosos brasileiros: a Barquinha, o Santo Daime, e a União do Vegetal. ${ }^{4} \mathrm{~A}$ ayahuasca também vem sendo utilizada de diversas outras formas, inclusive terapeuticamente (Labate 2004). Uma das características mais marcantes do efeito do uso desta bebida é a presença de "visões" ou imagens mentais espontâneas, denominadas mirações (ver Mercante 2002, 2004, 2006a, 2006b, 2006c, 2010; Shanon2002).

Um dos fatos que devem ser levados em consideração sobre o atual trabalho é que as instituições brasileiras estudadas estão em uma situação legal ambígua. A ayahuasca foi regulamentada em 2010 apenas para o uso religioso, desvinculando a prática terapêutica dos efeitos do chá, baseando eventuais curas em "atos de fé" (GMT 2006:10). ${ }^{5}$ Assim, o GMT recomendou que o uso terapêutico do chá ficasse em suspenso até que experimentações humanas pudessem ser realizadas para avaliar se este uso é seguro. As instituições pesquisadas alegam só empregá-la em suas práticas religiosas. 
Contudo, tais práticas possuem um efeito terapêutico, ainda que este seja atribuído ao ritual.

Curiosamente, um dos centros pesquisados possui título de Utilidade Pública conferido pela Câmara Municipal local, e outro está ligado às Secretarias de Saúde e da Justiça de seu estado. Takiwasi é uma das poucas comunidades terapêuticas no Peru que possuem um reconhecimento legal, expedido pela Dirección Regional de Salud de San Martin (Saldaña \& Guirrimán 2008).

Ao longo do trabalho de campo foram feitas 50 entrevistas, sendo $25 \mathrm{com}$ "pacientes" e 25 com "cuidadores". ${ }^{6}$ No contexto desta pesquisa, conceitos como "terapia" e "terapeuta", podem ser ampliados. Na Caminho de Luz, nenhum dos "cuidadores" passou por um treinamento formal. Em Takiwasi, os "curanderos" ou "maestros" responsáveis por dirigir não apenas os rituais com ayahuasca, mas as outras sessões que envolvem o uso de plantas (ver descrição abaixo) podem ser psicólogos ou não, pois curandeiros, indígenas ou vegetalistas em formação profissional também ocupam esta função. No Céu da Nova Vida e no Céu Sagrado os responsáveis por administrar a ayahuasca não possuem formação na área de saúde. Como coloca Calabrese (1997:244):

o termo "terapia" [pode ser utilizado] de forma ampla para referir a um tipo onipresente de atividade humana, cujas diversas manifestações dão suporte ao que chamamos de saúde mental. A construção de um significado terapêutico não é derivada somente a partir da intervenção consciente de um curandeiro especialista. Ela pode ser "construída" dentro de um modelo cultural ou surgir espontaneamente na pessoa.

\section{Ritual, espiritualidade, religião e religiosidade}

Creio ser importante deixar claro o que quero dizer com "religiosidade" e "espiritualidade". Utilizo o termo ritual como um sinônimo de "cerimônia", como um evento ordenado que busca criar um espaço para um contato com um universo transcendente identificado por meus informantes como "espiritual". Segundo Magnani (1999:51):

pode-se dizer que numa ponta está a religião, sistema institucionalizado de crenças e rituais a cargo de um corpo de especialistas; a religiosidade pode ser entendida como um estilo peculiar e coletivo de expressar o sentimento religioso; enquanto espiritualidade refere-se a uma experiência pessoal expressa em formas idiossincráticas individualizadas. 
Csordas (1994) coloca a origem da religião, "sua fonte experiencial, seu cerne fenomenológico" (:164), na tese de que a religião é "baseada em e elaborada a partir de um senso primordial de alteridade" (:164). Assim, na medida em que, para Csordas, a alteridade é parte da estrutura de "estar-no-mundo", a religião seria "inevitável, talvez até necessária" (:164). Desta forma, haveria um "impulso religioso que inevitavelmente se tornaria culturalmente elaborado em uma miríade de formas simbólicas, institucionais e experienciais" (:173).

Seguindo esta linha de pensamento, não basta fazer uma diferenciação entre "espiritualidade", "religiosidade" e "religião". Haveria, talvez, este cerne experiencial de que fala Csordas correndo por baixo destas três noções. A diferenciação conceitual nestas três instâncias remete, em outro nível, à antiga discussão sobre as diferenças entre "magia" e "religião", entre público e privado, entre individual e social. Conceitualmente há sim uma diferença, mas será que nas experiências com ayahuasca ela existe? Haverá, de forma estanque, tal separação entre o ritual e o foro íntimo da experiência "privada"?

Simmel (2010a) coloca que "até agora, a religião sobreviveu às religiões, tal como uma árvore sobrevive à colheita periódica de seus frutos" (:11), sendo "uma atitude íntima da alma" (:11). Simmel (2010b) questiona se as relações sociais dariam origem à religiosidade. Para ele:

a religiosidade não cria uma esfera transcendente mediante a destilação do espírito a partir de formas sociais empiricamente existentes, mas ela mesma produz uma esfera sociológica que se reflete de volta sobre a constituição psíquica do estado religioso íntimo. [...] Neste caso, a relação do estado religioso interior com as formações sociológicas permeadas por esse estado - pois essas formações já pertencem à igreja — não mais eleva até a esfera transcendente, mas conduz para trás e para o interior, para plenas formas psíquicas da religião (:70).

Simmel consegue então delinear a relação entre a instituição religiosa e a experiência da religião. A experiência leva ao transcendente, enquanto a vivência da instituição conduz a uma reformulação da psique individual através da assimilação dos ditames morais e de conduta apregoados por tal instituição. O tratamento feito com o uso da ayahuasca se coloca então sobre estes dois pilares: a experiência espiritual como processo vital, proporcionada pelo uso do chá durante os rituais, e a vivência íntima dos ditames morais e de conduta apregoados pela instituição, mesmo quando esta instituição não é religiosa (como em Takiwasi).

O dependente vive em um universo conflituoso, onde "bem" e "mal" se combatem e tentam se anular, onde o prazer é buscado de forma contínua, 
mas se vivencia o "mal absoluto" que há no mundo. Simmel (2011) coloca que a religiosidade, longe de acabar com essa dualidade, cria uma forma de convivência entre tais pares de opostos. Assim, o dependente alcança a paz que tanto deseja, não por ter eliminado os opostos. Segundo Simmel:

toda religiosidade é incompleta e dependente das contingências do destino individual se ela se baseia num único dos seguintes sentimentos: submissão ou elevação; esperança ou amargura; desespero ou amor; paixão ou calma. Mesmo que um desses sentimentos por fim venha a dominar, a natureza da religiosidade é dar espaço igual a todos esses pares de opostos. Isso não quer dizer que a religiosidade, já existente em nós, desencadeie ou acolha esses sentimentos; ao contrário, a religiosidade é que faz com que eles - normalmente provocados pelos contrastes do mundo e de nosso destino - agora fluam juntos, como as ondas de um rio. Graças à religiosidade, essas forças conflitantes apontam para a unidade secreta de um sentido mais profundo (2011:32).

A dualidade original, da qual o dependente não conseguiria escapar e que o empurraria ao consumo desenfreado, é vista por Simmel (2011) como "o vazio e a indiferença situados entre o reino da claridade e do ideal e o reino do pesado e tosco, como uma barreira intransponível que impossibilita o embate direto entre ambos" (:35). O dependente, de acordo com a visão das instituições pesquisadas, estaria preso nesse "vazio". Lá não existe a possibilidade de que o que "há de melhor em nós" encontre apoio e instrumentos para "erradicar o mal - esse mal está lá, simplesmente, e não luta de modo efetivo" (:35). A saída que Simmel (2011) indica, então, é a transcendência através da reconciliação com Deus. Curiosamente, esta é a experiência que direcionará a adesão ao tratamento de vários dos pacientes entrevistados.

\section{Dependência e seus tratamentos}

Berridge (1994) indica que as noções de adicção e dependência foram "descobertas" no século XIX, ainda que as ideias de "embriaguez crônica" e "habituação às drogas" já fossem conhecidas desde o século anterior. No século XVIII, ainda não era feita uma diferenciação entre o desejo e a vontade de consumir uma substância psicoativa e, para Berridge, tal distinção foi central para a elaboração do conceito de adicção. No século XIX havia uma "conjunção de forças políticas, culturais e sociais que deu hegemonia a esses conceitos" (Berridge 1994:17), aliada à reivindicação da classe médica pelo reconhecimento de sua autoridade científica. 
A "descoberta" da adicção, no caso do álcool, se deve a Thomas Trotter (Berridge 1994), com o livro Essay medical, philosophical, and chemical on drunkness, de 1804, no qual dizia que a adicção era uma doença que devia ser tratada por médicos. ${ }^{7}$ Em relação às drogas, Edward Levinstein (1878), em Morbid craving for morphine, considerava que o "morfinismo" era uma doença similar à dipsomania. George Harley, em Contribution to discussion. Proceedings of the Society for Study the Cure of Inebriety (1884:38), coloca então que a embriaguez era algo hereditário, assim como a loucura (Harley apud Berridge 1994).

Em 1964, a expressão "dependência de drogas" passa a ser utilizada, e ela é definida como "um estado resultante da administração repetida de uma droga, de modo contínuo ou periódico [...] ela pode ser química e, algumas vezes, física, sendo a base bioquímica a verdadeira força propulsora" (Berridge 1994:24). Em 1977, a Organização Mundial da Saúde passa a utilizar a ideia de "síndrome de dependência do álcool" e de "deficiências relacionadas ao álcool" (:24). Berridge coloca que tais definições da OMS tinham motivos políticos, visando manter o poder da classe médica sobre o assunto. Em resposta surgiu a ideia dos "problemas relacionados ao álcool" (p. 25), tendo como objetivo, de certa forma, abrir espaço para tratamentos outros que não os baseados na biomedicina, e o "desejo de se encontrarem alternativas de baixo custo para o tratamento médico hospitalar; o 'problema' implica uma solução rápida, ao passo que a 'doença' pode ser uma condição permanente" (:25).

Babor faz uma relação de diferentes modelos de estudo da dependência, que resultam, por sua vez, em distintas práticas de tratamento. O "modelo médico" trabalha com a noção de que a dependência tem uma origem física, sendo uma "doença", portanto, necessita de tratamento médico apropriado para que seja controlada. Esta perspectiva há bastante tempo foi popularizada por E. M. Jellinek, em The disease concept of alcoholism, de 1960, citado por Heath (1987). Em 1966, a American Medical Association passa a considerar o alcoolismo como uma doença e, em 1988, a adicção em drogas. Este modelo visa, segundo Babor, chamar a atenção da classe médica para o problema e influenciar os planos de saúde a incluírem este tipo de tratamento nos seus programas.

Heath (1987) indica ainda que o livro de W. Madsen, The american alcoholic: the narure-nurture controversy in alcoholic research and therapy, de 1973, baseado em uma análise sociocultural entre os Alcoólatras Anônimos, teve forte influência na visão do alcoolismo como uma doença biopsicossocial (ver também Campos 2005).

Os modelos "psiquiátricos" e "psicológicos" trabalham com a ideia de que a dependência é uma doença mental, podendo ser o sintoma de 
algum conflito psicológico anterior ou um "transtorno do comportamento" (Babor 1994:42), com ênfase no ambiente onde se iniciaria e se manteria a dependência.

É interessante notar que as instituições que fizeram parte da minha pesquisa possuem estas noções como uma base de seus tratamentos, ainda que haja algumas peculiaridades: Takiwasi, por exemplo, segue de perto a abordagem psicológica e comportamental, enquanto o Caminho de Luz coloca a dependência como o sintoma de um problema de ordem espiritual.

Há ainda as "definições científicas" buscando uma abordagem mais "operacional, a fim de facilitar a pesquisa experimental e o discurso acadêmico" (Babor 1994:47). Segundo Babor, as principais definições deste tipo são aquelas que têm origem na psicologia cognitivo-comportamental e na farmacologia comportamental, sendo uma alternativa aos modelos médicos, pois evitam traçar pressupostos baseados nas bases biológicas ou psicológicas da dependência. Busca-se aqui focar a atenção no comportamento observável do dependente (Babor 1994).

Finalmente, Babor coloca que, por não haver uma única visão sobre o que é dependência, não há uma única forma para avaliar as diversas definições que existem neste universo. Assim, segundo este autor, "o que existe [...] são perspectivas culturais específicas associadas a teorias sociais de dependência, cada uma das quais predizendo diferentes tipos de significado" (:52).

Antes de seguir adiante, porém, é válido indicar que o uso de psicoativos para o tratamento de dependência não é uma prática recente. Os editores da extinta Psychedelic Review (Editors 1963) apresentam uma revisão de alguns trabalhos sobre o uso de psicoativos para o tratamento de alcoolismo. ${ }^{8}$ O LSD foi utilizado nestes estudos, feitos segundo uma perspectiva médica e/ou científica. ${ }^{9} \mathrm{O}$ tratamento com LSD seguia basicamente dois sistemas: o psiquedélico, quando eram administradas grandes doses de psicoativos em poucas sessões; e o psicolítico, quando eram fornecidas pequenas doses por um longo período de tempo, sendo acompanhado ou não de psicoterapia (Halpern 2007).

Uma breve revisão da literatura até o momento indicou que diferentes psicoativos vêm sendo utilizados como ferramenta para a superação de dependência: a ayahuasca (Cemin et al. 2000; Labate et at. 2010; Labigalini Jr. 1998; McKenna 2004; Moir 1998; Ricciardi 2008; Santos et at. 2006); a maconha - Cannabis sativa (Labigalini Jr. \& Rodrigues 1997; Labate et al. 2010); o peyote - Lophophorawilliansii, cactus mexicano rico em mescalina (Halpern et al. 2005); a iboga - Tabernantheiboga, arbusto africano cuja raiz contém ibogaina (Alpert et al. 2007); o LSD (Yensen \& Dryer 1999). ${ }^{10}$ 
Com exceção do LSD, há uma tentativa de mesclar os modelos médicos/ científicos com um novo modelo, que teria origem fora do contexto ocidental, ainda que a ayahuasca, o peiote e a iboga sejam utilizados por diversos povos originários para resolver distintos problemas, mas não a dependência.

Takiwasi faz uma mescla do modelo psicológico com a medicina tradicional peruana. Ambos os modelos se confundem, se misturam, gerando práticas e explicações diferenciadas e únicas. Foi bastante frequente nas entrevistas realizadas em Takiwasi a ideia de que a dependência é um problema "menor", fruto de um distúrbio de comportamento anterior. Mas também são levados em consideração problemas de ordem "espiritual" - explicação que teria origem na medicina tradicional peruana, dando origem a um tratamento que inclui dietas, purgas, saunas, sessões de ayahuasca, em que se visa limpar "descarregar" — os pacientes. Sem tal "descarrego espiritual" não existe a possibilidade de serem trabalhados os problemas psicológicos.

Em outro extremo desta mistura de modelos, temos o Caminho de Luz. Nele o que acontece é uma apropriação "popular" do conhecimento baseado nos modelos médicos ou psicológicos. Tal conhecimento é então encaixado e ressignificado dentro de práticas únicas. No Caminho de Luz se entende a dependência como uma "doença espiritual", cuja cura se dá através do uso do "Vegetal".

Esta nova modalidade de tratamento poderia ser chamada de "modelo da ayahuasca", um modelo que faz uma mistura entre os sistemas "psiquedélico" e "psicolítico", pois grandes doses de psicoativos são ministradas por longos períodos de tempo.

\section{Os Centros de Tratamento pesquisados}

\section{Takiwasi}

Takiwasi foi fundada pelo médico francês Jacques Mabit, em 1992, em Tarapoto, na Amazônia peruana (ver Bustos 2008; Giove 2000; Mabit 2002, 2006, 2007; Mabit et al. 1996; Moure 2005; Saldaña \& Guirrimán 2008; Sieber 2007). Além da ayahuasca, há o emprego de diversas técnicas, como as dietas e as "purgas" (uso de plantas para provocar vômitos, entendidos como purificatórios e terapêuticos), juntamente com acompanhamento psicológico (para outros exemplos de uso de medicina tradicional em tratamento de dependentes em outros países, ver Heggenhougen [1984]).

Um momento bastante importante é o do processo de entrada em Takiwasi. O paciente recém-admitido não é colocado diretamente no grupo, 
que já está com o tratamento em andamento. O novato é submetido a um período de isolamento de 15 dias. Durante esse tempo ele fará, além de um exame médico inicial, varias sessões de purga e um enema. A purificação inicial ajudaria o paciente a passar pela fase mais intensa da interrupção do uso de drogas, que pode envolver crise de privação e "craving". Procura-se também atenuar o "choque" que a entrada deste paciente no grupo pode causar, pois o novato traria com ele, de maneira muito viva e intensa, a "energia" da rua, das drogas. Isto causa problemas para os que estão no tratamento, que percebem a si mesmos mais "limpos" e "purificados".

O tratamento é estruturado em três eixos: uso de plantas, psicoterapia e convivência. As plantas são "personagens" (uma vez que são dotadas de agência) centrais nas dietas e nas purgas, sendo também tomadas como plantas de contención. Elas são vistas como "seres espirituais" encarnadas em um corpo vegetal, atuando além da sua "ação química", sendo um "ser inteligente" que é introduzido no corpo do paciente para auxiliá-lo no tratamento (ver Henman 2008; Lenaerts 2006 sobre o uso de plantas entre os Ashaninkas em que há o mesmo tipo de entendimento). Harrington (2008:11) coloca que as plantas são vistas pelos pacientes e pelos psicólogos como capazes de deixar clara a "severidade de seu problema com as drogas, iluminar as raízes emocionais deste problema, limpar energeticamente o corpo, clarear o sentido de valor dos pacientes e reconectar os pacientes com seus corpos".

As purgas são rituais que antecedem o ritual com a ayahuasca, realizadas na tarde do dia anterior a uma sessão de ayahuasca. Os participantes se dirigem a uma "maloca" específica (distinta da maloca onde se bebe ayahuasca) por volta das 15h. Lá encontram vários bancos baixos e baldes, dispostos em roda. O curandeiro que dirigirá a cerimônia se senta em uma cadeira no centro da maloca. Ele serve às pessoas as doses de plantas purgativas, soprando-as com tabaco, o mesmo fazendo com as pessoas presentes (o curandeiro sopra sobre a cabeça, o peito e as mãos de cada paciente a fumaça de um "mapacho" - cigarro de tabaco forte). Em seguida, ele começa a cantar os ícaros — canções utilizadas no vegetalismo peruano - (ver Luna 1986) e, aos poucos, as pessoas começam a vomitar. Diversas plantas são utilizadas, e cada uma possui características próprias, sendo administradas de acordo com o momento em que cada paciente se encontra no processo terapêutico. Por volta das 17 h30 a sessão é encerrada, e é recomendado que as pessoas fiquem em jejum até a manhã seguinte. As purgas podem ser tomadas fora deste ritual, sempre que um paciente sente necessidade desta intervenção. É bastante comum pacientes pedirem purgas quando se sentem agitados, ansiosos ou carregando "energias negativas". ${ }^{11}$ 
As dietas são períodos de isolamento, acompanhados da utilização de plantas. As pessoas ficam em um pequeno "tambo" - casa simples, de madeira, aberta em uma das paredes, onde se encontra apenas uma cama e um mosquiteiro - por oito dias. A dieta se inicia sempre em um sábado. Há a ingestão de plantas, cada uma com suas propriedades terapêuticas específicas (cada pessoa toma uma planta durante a dieta). As dietas acontecem na chácara de Takiwasi (a $4 \mathrm{~km}$ do centro de tratamento, no meio da mata) na sexta-feira. Nesta noite, as pessoas participam de uma sessão de ayahuasca e, quando esta termina, já na madrugada de sábado, a dieta tem início. É permitido que cada participante coma uma porção de arroz por dia, acompanhada de duas bananas verdes, sendo vedado o consumo de sal e açúcar. A restrição de açúcar se estende ainda por mais 15 dias após o período de isolamento. A dieta termina no sábado subsequente, com a ingestão de uma combinação de cebolas, limão, salsa e sal. A dieta é um período de purificação profunda, quando os sonhos se tornam extremamente intensos. Tais sonhos são trabalhados posteriormente em sessões de psicoterapia.

A psicoterapia faz a catalisação do entendimento adquirido, seja nas sessões de ayahuasca, seja em outros momentos do tratamento. Há também os "talleres": yoga, arteterapia, psicodrama etc. Os sonhos são muito importantes, e toda segunda-feira, às $20 \mathrm{~h}$ há um "taller" de interpretação de sonhos. Às sextas há a "convivência", que junto com as reuniões de "pós-ayahuasca" (realizadas alguns dias depois das sessões com o chá) formam um espaço de terapia em grupo, além de ajudarem na organização da vida comunitária dos pacientes.

Na chamada "ergoterapia", que vai das 8 h30 às 12h30, todos os dias (exceto aos domingos), são realizados trabalhos físicos, como consertos, limpeza e arrumação de Takiwasi, o que força os pacientes a trabalharem fisicamente e em grupo.

\section{Centro de Recuperação Caminho de Luz}

O Centro de Recuperação Caminho de Luz está localizado em Rio Branco, Acre. É liderado pelo Mestre Muniz, que em 1993 começou a tratar dependentes. Seu irmão foi seu primeiro "paciente". Este centro segue a ritualística utilizada na União do Vegetal.

Era cobrado na época do trabalho de campo (2009 e 2010) um "auxílio" no valor de $\mathrm{R} \$ 150$, uma vez que não é obrigatório o pagamento. A maioria das pessoas ali internadas vem das camadas mais pobres da sociedade, ainda que pessoas de médio e alto poder aquisitivo também busquem o centro. 
Em 17 de novembro de 2009 havia 98 internos nas três unidades de Caminho de Luz, sendo 73 homens e 25 mulheres. Estas três unidades estão na Vila Acre, bairro periférico de Rio Branco (onde está a grande maioria dos internos), na cidade de Bujari, e no Amazonas, na margem do Purus.

Este centro de recuperação é ligado à Sesacre (Secretaria de Saúde do Estado do Acre), via Cades (Central de Articulação das Entidades de Saúde do Acre). A Cades dá um auxílio para manter 20 pessoas em regime de internato, além de pagar o valor de um salário mínimo para manter dois monitores, mas que acaba sendo dividido por quatro pessoas que ocupam esta posição.

Na Vila Acre funcionam duas instituições distintas: o internato propriamente dito, onde ficam as pessoas em tratamento, e a "comunidade", onde moram pessoas que não tiveram condições de retornar a um lar depois que seus tratamentos terminaram, como ex-moradores de rua. Algumas pessoas da comunidade trabalham na marcenaria (juntamente com alguns internos em final de tratamento), outros trabalham fora, e outros ainda buscam doações para o funcionamento de Caminho de Luz.

Cada dupla de internos dorme em uma casa de apenas um cômodo. Além da horta e do local onde são feitas as sessões, existem duas cacimbas para banho. O lugar onde são realizadas as sessões é denominado "Salão", um espaço retangular, sem paredes, sem piso, com teto de palha, bancos toscos de madeira e algumas cadeiras. Em uma das suas extremidades está uma mesa coberta com um pano branco onde fica o Vegetal e uma vela. De lá o "mestre" dirige a sessão.

O tratamento está totalmente baseado no Vegetal, denominação local da ayahuasca. Assim que chega ao centro, o interno passa a tomar três doses diárias do chá: de manhã, depois do almoço e ao anoitecer. Este é o momento de desintoxicação e de controle, segundo Mestre Muniz, da "crise de privação". Na medida em que o interno se "acalma", ele passa a beber o Vegetal apenas uma vez por dia, nas reuniões noturnas. Nas quartas-feiras são realizadas as "Sessões de Acerto" e, nos sábados, as "Sessões de Escala". ${ }^{12}$

Nas reuniões, há um aparelho de som onde são colocados CDs diversos, e a música cria um fundo sobre o qual a "burracheira" (a forma como o efeito do chá é denominado) acontece. Por outro lado, as sessões de Acerto e as de Escala seguem o estilo da União do Vegetal (ver Brissac 1999): depois da distribuição do Vegetal, é rezado um Pai Nosso, e todos bebem o chá juntos. Em seguida, são feitas diversas "chamadas", com canções entoadas por uma única pessoa (neste momento apenas o dirigente da sessão canta, mas durante a sessão outras pessoas podem realizar as chamadas), que servem para fazer a "abertura" da sessão e "chamar a força" e a "proteção" para 
ela. São também tocadas músicas de CDs, que são escolhidas em função da "mensagem" que trazem, ou seja, a capacidade de evocar temas considerados importantes, como família, liberdade, orações a Deus pedindo força, proteção, perdão, o perigo das drogas e da bebida etc.

A diferença básica entre os dois tipos de sessões é que a de Escala é para a "elevação espiritual", ao contrário das Sessões de Acerto, nas quais as dificuldades do convívio em grupo são colocadas abertamente para que o dirigente aconselhe as partes envolvidas nas várias contendas.

Em uma das Sessões de Acerto, depois de algumas chamadas e músicas, o Mestre abriu um espaço para que todos pudessem falar. Um interno veio à frente e, aos prantos, pediu: "Mestre, eu quero uma chance de ser uma boa pessoa, limpinha, do fundo do meu coração". Esta pessoa estava em fase final de recuperação. Não estava mais vivendo entre os internos, e havia passado a dormir em uma rede ao lado da casa do Mestre, enquanto esperava condições para construir sua casa na comunidade. Mais tarde, ele me disse que havia sido o motorista do Mestre (pois já fora motorista de caminhão), mas que havia recaído, e que agora estava se recuperando. Ele também me disse que sua esposa estava chamando-o para ir de volta para casa. Ele me pareceu temeroso de dar esse passo fora da comunidade.

Durante esta sessão, o Conselheiro Antônio disse algumas frases que servem para motivar e direcionar o tratamento dos internos: "Deus é tudo na nossa vida, é tudo que temos para buscar. Temos que nos ajoelhar perante Deus". A luta contra a dependência é um posicionamento motivador e acontece o tempo todo: "Para seguirmos nesta caminhada, temos que lutar"; "Cada um tem que procurar nascer de novo"; ou ainda, "Você só tem uma meta: vencer. Ou você vence ou você será vencido. O Vegetal é um instrumento poderoso, para você lutar. Você tem que se dar a oportunidade de adquirir o conhecimento".

O Conselheiro Antônio procurou também enfatizar que o trabalho de recuperação é de cada um ali presente, e não apenas do Vegetal: "O Vegetal faz uma parte do trabalho, a parte mais difícil, limpa, no mais íntimo do ser. Mas cada pessoa tem que buscar dentro de si, procurar limpar, sem mágoa, ódio, rancor, pois essas são forças que não evoluem". Trabalha-se muito a questão da disciplina: "Aqui é um lugar para obedecer. Aqui vamos lutar juntos e vamos conseguir. A obediência é o caminho para todos nós. A obediência começa na prática, dentro do Salão do Vegetal".

Tanto as reuniões quanto as sessões são espaços para testemunhos: de cura, de doença, de força, de fraqueza. São confissões, arrependimentos públicos, desabafos. As reuniões são momentos nos quais as diretrizes de comportamento e conduta são ditadas, não por um manual com regras, 
mas por depoimentos de pessoas que passaram (ou mesmo ainda passam) por problemas iguais aos que a maioria dos internos ali está passando. São palavras de ex-dependentes (ou de pessoas que também estão em tratamento), com larga experiência no assunto, e que exatamente por isso têm sua opinião respeitada.

A reunião é uma preparação para a gente amanhecer o dia bem, com paz, harmonia. A pessoa que falta à reunião vai enfraquecendo na sua caminhada. Uma preparação para todos aprenderem a se comportar no dia a dia, aprenderem a se concentrar quando bebem o Vegetal. A União do Vegetal é de concentração mental, a pessoa tem que se aquietar, se acalmar, para receber o que tá precisando Aqui é o caminho de Deus que mostra a realidade para a pessoa. É a pessoa zelar, se dedicando ao máximo e obedecendo às ordens da direção. Nós estamos aqui para caminhar no caminho certo de Deus. Aqui, nesse local, a pessoa vem se preparando para passar pelas dificuldades na vida. Esse Vegetal vai mexer no nosso sentimento (Conselheiro Pedro - Reunião dia 01 de dezembro de 2009).

O "querer se tratar" é bastante evidenciado durante tais falas. Por exemplo, na reunião do dia 26 de novembro de 2009 a Conselheira Paula, esposa de outro conselheiro, monitor e ex-dependente, disse: "A pessoa que vem se tratar aqui tem que ter o querer. Aqui a gente tem esse chá milagroso, o Vegetal, que transforma vidas". Este querer, no entanto, é só o primeiro passo. O Vegetal é o suporte para que tal vontade se concretize.

Mas a família também é outro pilar importante no processo de tratamento. Muitos dos relatos que coletei sobre as experiências durante a(s) primeira(s) vez(es) em que se usou o chá contam de um arrependimento profundo, de uma tomada de consciência do mal que o dependente causava à sua família, que acabou,muitas vezes, por se afastar do dependente, abandonando-o à sua própria sorte. Surge a vontade de reatar os laços de contato com a família, o que se daria pela adoção de um comportamento "correto". Como disse o Conselheiro Gustavo: "A gente fazendo as coisas direito o Mestre toca no coração da família da gente, e eles passam a ajudar".

Outro foco de motivação e manutenção da comunidade vem da ênfase que é dada ao fato de que, após ter se curado, a pessoa deve buscar curar os outros que estão passando pela mesma dificuldade: "No internato vocês têm a chance de cuidar de si mesmos, para depois poderem dar a mão aos outros que precisam" (Conselheira Paula).

A dependência não é encarada como uma doença "física", mas espiritual, sendo, na verdade, um reflexo deste problema espiritual. Segundo o 
Conselheiro Gustavo, "Muitas vezes a pessoa chega aqui e ela não é doente [por causa] da química, mas espiritualmente".

\section{Centro Espiritual Céu Sagrado}

O Céu Sagrado está em Sorocaba, São Paulo. Além do tratamento de dependentes, este centro distribui, desde 2003, marmitas para a população carente. O centro possui o título de "Utilidade Pública" da Câmara Municipal (ver Labate et al. 2010).

No início, os atendimentos no Céu Sagrado eram feitos durante um ritual semanal de cura. Com o passar do tempo, Fernando Dini e seu irmão Luciano, líderes desta Igreja do Santo Daime, resolveram montar um "prontosocorro" na empresa de reciclagem de lixo que possuem em Sorocaba.

O "pronto-socorro" é composto de duas salas e dois banheiros. Lembra muito uma pequena enfermaria, com suas paredes de azulejos brancos, chão e teto também brancos. Na sala de entrada fica uma mesa (igualmente branca), atrás da qual se senta Jardel, responsável pelos atendimentos. Um balcão onde fica o Daime e os copos, um galão de água, foto do Mestre Irineu e a placa com o CNPJ do Pronto-Socorro completam a decoração do ambiente.

Na sala onde os atendimentos propriamente ditos ocorrem há algumas cadeiras que parecem antigas cadeiras de dentista, acolchoadas e um tanto reclinadas. Jardel, ao servir $600 \mathrm{ml}$ de Daime, diz sorrindo ao paciente: "Receba a sua cura". O paciente dirige-se para as cadeiras e permanece em silêncio. O próprio Jardel não bebe o Daime.

Muitos pacientes têm vômitos e diarreias. Isto é encarado como uma "limpeza" (assim como em Takiwasi e no Caminho de Luz), pois as toxinas acumuladas no corpo devido ao uso de drogas são "eliminadas".

Após mais ou menos uma hora e meia, dependendo da intensidade da experiência da pessoa, Jardel pode administrar mais uma dose de Daime, desta vez em menor quantidade. Ao final da experiência, Jardel comenta sobre a cura que a pessoa está recebendo, sobre os milagres que o Daime proporciona, e sempre faz um convite para que a pessoa vá visitar a Igreja na próxima cerimônia.

Desta forma, os que conseguem dar continuidade ao seu tratamento o fazem na Igreja. Outros retornam para um atendimento no Pronto-Socorro, caso sintam necessidade de fazê-lo (é recomendado a eles que, a partir daquele dia, sempre que sentirem vontade de usar droga, que venham ao Pronto-Socorro, quando lhes será administrada uma dose de Daime). Muitas 
pessoas não retornam nem ao Pronto-Socorro nem vão à Igreja. Vários dos fardados do Céu Sagrado já passaram pelo Pronto-Socorro.

Uma vez na Igreja, passam a participar dos trabalhos do calendário ritual do Santo Daime. Na verdade, os trabalhos do Céu Sagrado, mesmo sem serem necessariamente voltados para o atendimento dos dependentes, acabam por ter uma grande ênfase na cura deste problema, ênfase esta que aparece com bastante frequência nos discursos de Luciano e Fernando dentro da Igreja.

\section{Centro Espiritual Céu da Nova Vida}

O Céu da Nova Vida está localizado em São José dos Pinhais, na grande Curitiba, Paraná. É dirigido pelo Padrinho André Volpi Neto, 42 anos (em 2010), curitibano, formado em administração de empresas, e que possui há 17 anos uma empresa de propaganda de plásticos. André é um ex-paciente do Céu Sagrado. Começou a utilizar drogas aos 18 anos de idade. Foi dependente de cocaína por 13 anos, tendo tentado diversas formas de terapia, inclusive religiosas. Seu pai soube do trabalho realizado no Céu Sagrado (importante frisar que André nunca havia ouvido falar da ayahuasca antes). No dia 26 de junho de 1999 participou de um ritual de cura no Céu Sagrado e, desde então, interrompeu o uso de drogas. No ano seguinte recebeu, durante um ritual no Céu Sagrado, a "inspiração" de iniciar o atendimento aos dependentes em Curitiba. Finalmente, em 2001, deu início ao Centro Espiritual Céu da Nova Vida.

Até maio de 2010 o atendimento aos dependentes era realizado semanalmente em um ritual de cura especialmente montado para este fim (ver Schneider 2010). Contudo, André percebeu que este sistema era falho, pois fazer um dependente esperar por até uma semana para participar de um ritual era bastante difícil. Assim, depois de conversar com os dirigentes do Céu Sagrado, passou a adotar um sistema de atendimento similar ao deste centro, ou seja, diário, passando então a ser feito na Igreja do Céu da Nova Vida por dois ex-pacientes, fardados, Felipe e Marcos, contratados pela Igreja para cumprir tal função.

O salão da Igreja é amplo, medindo $25 \times 25 \mathrm{~m}$. O teto é branco, e nele há uma grande estrela de seis pontas em baixo relevo, ao centro. Esta estrela, durante os trabalhos, tem as luzes ao seu redor acesas. As paredes do salão também são brancas, assim como o piso.

A decoração consiste em um quadro com o busto de Mestre Irineu, à entrada, junto com outro quadro onde há um beija-flor. Na parede à direita 
de quem entra há um quadro retratando Jesus Cristo, demarcando assim o lado dos homens (homens e mulheres ficam separados na Igreja). À esquerda temos um quadro de Nossa Senhora, indicando o lado feminino. Ao fundo há um painel de vidro, onde está desenhada uma estrela de seis pontas, dentro da qual há uma águia, sobre ela uma cruz de Caravaca, uma lua crescente à direita, e um sol à esquerda. Ao redor da estrela se lê: Centro Espiritual Céu da Nova Vida - Santo Daime.

Uma mesa em forma de estrela de seis pontas fica em posição central na Igreja, um tanto deslocada para o fundo. Durante os rituais (mas não durante os atendimentos), o centro da Igreja é ocupado pelos músicos. Esta é uma inovação em relação àquilo que normalmente acontece nas Igrejas do Santo Daime, onde em geral a mesa está no centro da Igreja, e ao redor dela se posicionam os músicos.

Embaixo do retrato de Jesus há um pequeno balcão - uma superfície de vidro apoiada sobre duas pilastras brancas - lugar em que se serve o Daime para os homens. Sobre este balcão há uma vela acesa. O mesmo se dá do lado das mulheres.

As pessoas, para participarem dos atendimentos na parte da manhã, devem chegar até as $9 \mathrm{~h}$, e à tarde, até as $14 \mathrm{~h}$. O atendimento é feito em total silêncio. Ocasionalmente, pode ser cantado um hino do Santo Daime. A abertura do atendimento é feita com um Pai Nosso e uma Ave Maria. São servidos em torno de $600 \mathrm{ml}$ de Daime para quem está sendo atendido. O encerramento é feito com os dois últimos hinos do Cruzeirinho do Mestre Irineu (os hinos são arrumados em hinários, e são "recebidos" por seus donos). Depois disso, são rezados um Pai Nosso, uma Ave Maria e a Prece de Cáritas.

\section{Algumas considerações}

A "onda" da droga e a "onda" da Ayahuasca: qual a diferença?

Uma das perguntas que fiz durante as muitas entrevistas conduzidas ao longo da pesquisa foi: "qual a diferença entre a 'onda' (ou o efeito subjetivo) da droga e a 'onda' da ayahuasca?". Para minha surpresa, várias pessoas atestaram que, inicialmente, não havia grande diferença. Muitos dos entrevistados relataram experiências de perseguição muito similares às que eles experimentavam quando, por exemplo, fumavam crack. ${ }^{13}$ Eu já havia colhido este tipo de relato quando da pesquisa sobre a Ablusa, em 2007 (ver Mercante 2009), instituição que utilizava o Vegetal na recuperação de moradores de rua em São Paulo. 
Contudo, a ayahuasca proporcionava outro tipo de experiência: o arrependimento, a crise de consciência. A frase "pude ver o mal que estava fazendo à minha família" foi repetida em muitas entrevistas.

O ambiente onde se está utilizando o crack ou a mela ${ }^{14}$ não ameniza em nada o sentimento de "paranoia", muito pelo contrário, estimula-o e provavelmente o amplia. Quando o dependente bebe o chá e este começa a fazer efeito, o medo retorna para este dependente. Contudo, há no uso do chá um ambiente ordenado, e há, acima de tudo, outras pessoas presentes que já passaram por esse processo e que vêm reconstruindo suas vidas com o apoio do chá. Assim, este sentimento inicial é superado, passa-se à crise de consciência, e depois à esperança de reconstrução de uma vida nova, de perdão, de amparo.

Este modelo aponta, mais uma vez, para uma profunda interação entre química e sociedade, ritual e experiência, neurofisiologia e cultura (ver Lende 2005). Não seria a droga per se que causaria a experiência do indivíduo, mas um processo muito mais complexo. Não é o crack ou a mela que causa a "paranoia", mas o contexto do uso desta substância. Como coloca Becker, de forma irônica (1967:163), "se a droga de fato provar ser a causa de uma psicose bonafide, este será o único caso no qual uma pessoa pode afirmar com autoridade que encontrou $a$ única causa deste fenômeno".

Não estou aqui querendo afirmar que o uso ritual de crack ou de mela possa ser a saída para a dependência. Se isso fosse possível, já teria ocorrido. Nem estou dizendo que a química não tem relação alguma com a "paranoia", mas sim que tal base bioquímica não é a única causa. Afinal, como coloca Simões (2008:16): "Sem dúvida é importante conhecer os produtos e suas propriedades, mas este é apenas um dos eixos da questão. É preciso levar em conta também a relação humana com tais produtos, as motivações e os sentidos ligados à produção e ao uso de substâncias específicas". Continuando com Becker (1967:166),

nós tomamos como 'dado' que o usuário inexperiente de drogas, ainda que ele queira ficar "chapado" ["high", no original em inglês], não espera uma experiência tão radical que coloque em jogo o senso comum sobre uma série de pressupostos. Em qualquer sociedade em que a cultura contenha noções de sanidade e insanidade, a pessoa que percebe seu estado subjetivo alterado pode pensar que ficou louco.

Assim, se a pessoa fica "higher" - mais "chapado" — do que espera, ela pode ter uma amostra do que é a insanidade, capaz de ser muito bem ser representada pela sensação de perseguição (a "noia") durante o efeito 
da droga. Este é o reino do caos, da não cultura, da não sociabilidade, sem regras. E, sem regras, a mente perderia seu suporte. É aqui que cessa o processo do uso de substâncias como o crack e a mela.

A diferença então se constrói no uso da ayahuasca. Aqui também há um momento de ruptura, de caos. Mas é construído um meio para que ideias sobre modos de sociabilidade, de vida, de prazer, de punição etc. venham a ser modificadas. Assim, durante esse período de transição entre ideias, o indivíduo pode se encontrar no mesmo reino de caos em que se encontrava antes. Contudo, esse "caos" é visto então como um sinal de mudança, de cura, pois se reconhece que se está exatamente nessa fase de transição.

Na verdade, a estruturação do "caos" viria de forma mais contundente no dia a dia do tratamento, no convívio com outras pessoas que tentam superar o mesmo problema. No caso de Takiwasi, há a psicoterapia - seja em grupo, seja individual - e há a convivência diária dos pacientes. Em Caminho de Luz, boa parte desse reordenamento se dá nas sessões e nas reuniões, como os momentos de perguntas e respostas "feitas na luz do Vegetal", mas também nas conversas informais. E, no Céu Sagrado e no Céu da Nova Vida, há a imersão na vida da Igreja. Como coloca Carneiro (2008:72), "a prevalência de um fluxo coletivo irrompe sempre que o edifício da subjetividade é abalado". O "fluxo coletivo" que irrompe durante o uso do crack ou da mela seria o fluxo do pânico, da tensão, da suspeita, da satisfação de uma necessidade "básica" (a "fissura") individual. Já durante o uso da ayahuasca o fluxo coletivo estaria baseado na irmandade, em "verdade, amor e justiça", na "luz", na reconstrução da própria vida.

Vargas (2008) faz considerações nesta mesma direção. O efeito das drogas estaria, para este autor, sempre articulado com "diferentes modos de engajamento com o mundo" (:56). Vargas indica que haveria então dois tipos de drogas: as que permitem viver a vida em "extensão", ou seja, ter uma vida mais longa; e as que, no caso de um uso não medicamentoso, "atualizariam outros modos de engajamento com o mundo, modos estes que se pautariam por considerar a vida não mais em extensão, mas em intensidade" (:56).

E é na manutenção de tal "intensidade" que modelos como os dos centros que utilizam a ayahuasca no tratamento da dependência se apoiariam, uma vez que não se propõem a trocar a droga ilícita por um modelo de vida sóbrio, mas sim que se passe a ter outro tipo de contato com a "intensidade". Não se nega o acesso ao êxtase, mas se cria um veículo estruturado e formal (no sentido de que se tem e se fornece uma forma, um molde, um modelo) para tal acesso. 


\section{Terapia de substituição}

Outra questão que surgiu ao longo desta pesquisa foi se o uso da ayahuasca não seria simplesmente um processo de substituição de uma droga por outra. O uso da ayahuasca (assim como o AA — ver Antze 1991, e o peiote ver Halpern et al. 2005; Garrity 2000) está voltado para um processo de reconstrução da vida do dependente.

Um exemplo claro de terapia de substituição pode ser encontrado no uso (legal) de metadona para tratar heroinômanos (ver Bourgois 2000). Aqui não há tal preocupação - a de reconstrução da vida do dependente - mas apenas o desejo de se manter o dependente em um estado socialmente produtivo. Burgois (2000) coloca que o uso de metadona é uma ferramenta de controle deste dependente. Tal suposição - que a ayahuasca seria uma terapia de substituição - estaria pautada exatamente na tendência de nossa sociedade de coibir os estados não ordinários de conscientização (ver Mercante 2010, 2012).

Marras (2008) coloca, por exemplo, que os efeitos das substâncias psicoativas não estariam na "substância em si", nem na "sociedade", mas na agência de uma sobre a outra, na rede entre ambas, e que nossa sociedade veria nas experiências com psicoativos um "excesso de subjetivação" (:175), excesso este que colocaria em risco a manutenção da vida em sociedade, tida como a contraparte objetiva da existência:

É como se a vida social, que se realiza como uma espécie de outro eu internalizado no indivíduo (o eu social), estivesse ameaçada de se desfazer pela ação da vida excessivamente subjetiva do mesmo indivíduo, que então precisa manter o equilíbrio, que é o social, a estabilidade. Manter a consciência é manter a estabilidade e é manter a sociedade - eis a ordem (Marras 2008:175).

[Dessa forma,] alterar a consciência seria uma grave ameaça de rompimento com essas redes amplas e contratuais que dão origem a esse constructo altamente valorizado do par indivíduo/sociedade. Por isso o uso de psicoativos, nessa mesma sociedade, deve ser controlado (como as bebidas alcoólicas e como todas as outras substâncias indexadas). O esforço por manter estável a subjetividade individual, isto é, a identidade física e consciente, civil e política da pessoa individual — ou desta noção individual de pessoa (...) Simetricamente, prevalece o desinteresse em se investigar e criar terapias a partir dessas substâncias, a despeito do comprovado sucesso, historicamente relatado, alcançado em pesquisas com psicodélicos (:179). 
Raiol Marcelo, técnico em dependência química que estava trabalhando na Caminho de Luz e que não bebia o Vegetal, colocou que

nesse mês em que fiquei observando, no período inicial, entre 10 e 15 dias, existe uma forma de substituição da droga. Parece que quando ele [o dependente] chega, ele vai atrás, a todo instante, do Conselheiro que serve o Vegetal, como se aquilo fosse uma espécie de "onda", de ele estar substituindo aquela sensação de relaxamento que a droga dá pra ele pela "borracheira" que o Vegetal dá pra ele, e este seria um uso inadequado do Vegetal. Mas a gente vê que isso é no início, quando ele não tem ainda conhecimento dos ensinamentos da própria União do Vegetal, da religião. Mas isso ajuda a desintoxicar de forma natural, trabalhando na ansiedade que o uso de drogas dá, devido à abstinência.

Oscar, paciente em Takiwasi, oriundo da Espanha, contou que "na Espanha se dá muito antidepressivo para tratar o uso de cocaína. Mas isto é como ter um doente para o resto da vida. Essa é uma pessoa que não pode se reinserir completamente na sociedade". Perguntei a ele então sobre a diferença entre o uso de metadona (no caso do tratamento da dependência de heroína) ou antidepressivos (para cocaína) e a ayahuasca, e ele disse que havia sim uma diferença, pois "a ayahuasca não causa dependência, e a metadona e os antidepressivos, sim. Aqui [em Takiwasi], tomas ayahuasca, mas no dia seguinte você não quer tomar. No meu caso, me sinto saturado de ayahuasca. Ela me mostra algumas coisas, mas depois quero colocá-las em prática. Não quero mais revelações, mas quero praticar".

Gabriel, também paciente em Takiwasi, francês, passou pela terapia de substituição de heroína por metadona:

quando eu tive essa adicção à metadona, aos psicotrópicos, que são drogas "legais", quando estive em um tratamento dado pelo Estado, me pareceu que era apenas para que eles [as outras pessoas] pudessem dormir mais tranquilos. Com o consumo de heroína, eu roubava, fazia coisas más para a sociedade, e dar metadona para os toxicômanos é dizer mais ou menos "que se droguem, mas não nos molestem mais". Só serve para que a sociedade tenha uma "boa consciência" de que está ajudando.

\section{Conclusão}

O trabalho com os grupos pesquisados se mostrou bastante rico. Mas, como se tratou de uma pesquisa pioneira, foram levantadas muito mais dúvidas 
do que respostas. E, exatamente porque se trata de um estudo pioneiro, sua função foi exatamente esta: avaliar a complexidade deste campo (ou campos, na medida em que se trabalhou com várias instituições) e apontar direções para que novas pesquisas sejam feitas no futuro, tanto com uma perspectiva geral (ou seja, quando o tema é ayahuasca e dependência), quanto particular (questões específicas e inerentes a cada instituição avaliada).

O que quero enfatizar aqui é que existe o que chamei de "modelo da ayahuasca". Neste modelo se trabalham, através do chá, as questões neurobioquímicas da dependência e as questões sociais. Modifica-se a química do cérebro/sistema nervoso e trabalha-se sobre questões psicológicas e de convivência, pois se entende que as modificações neurobioquímicas não se sustentam caso não seja modificado o ambiente (tanto interno/psicológico quanto externo/de convivência) onde este sujeito está inserido. A ideia é que o uso da ayahuasca traria à tona uma série de emoções que são gatilhos para o uso de drogas, permitindo que o paciente atue sobre estas emoções durante o efeito do chá. Caso o paciente não reconstrua seu mundo interno/ psicológico a partir de uma nova perspectiva e com isso modifique sua maneira de se relacionar com os outros (o que inclui participar de novos grupos sociais), a recaída é inevitável. Este é um dos pontos de apoio para se afirmar que o uso de ayahuasca para tratar dependência não é meramente uma terapia de substituição.

O que vemos ao longo do tratamento - além da "limpeza" física, psicológica e espiritual - é um processo de limpeza "moral". Mais uma vez, o "modelo da ayahuasca" alinha distintos modelos de tratamento. As diferentes instituições tentam convencer seus pacientes de que há um modo correto de estar no mundo, e que se tal modo for seguido, a chance de recaída é menor ou mesmo inexistente. Há uma ênfase muito grande em colocar a "droga" na esfera do "mal", do "erro". A ayahuasca, por sua vez, pertence "à luz", "à ordem", "à limpeza", ao que é "correto". Com esta operação, mais uma vez, o tratamento com ayahuasca afasta-se de uma terapia de substituição.

Há ainda outro contraste contundente: as drogas proporcionavam momentos de prazer intenso, resultando, contudo, na desestruturação da vida do dependente. Por outro lado, as experiências com ayahuasca (assim como com as plantas purgativas) podem ser extremamente desagradáveis, mas possuem um efeito estruturante na vida do paciente. Tal efeito é construído principalmente pela convivência com o grupo. Não é apenas a sensação de bem-estar físico que acontece no dia seguinte a uma sessão de ayahuasca, como foi descrito pelos pacientes que entrevistei, mas mesmo quando esta sessão é desagradável, ela é proporcional a uma limpeza "moral". Este bemestar é reforçado pela ação do grupo, e não só pela da instituição e de suas 
normas de conduta, e advém do convívio entre os pacientes, o que reforça os parâmetros do que é "bom" e do que é "ruim". A "cura" viria por uma adesão cada vez mais irrestrita ao lado "bom".

A transformação pessoal e social é alvo de diversos tratamentos. O AA faz disso o centro de seu processo. Como coloca Antze (1991), "Na verdade o AA faz mais do que ajudar o bebedor compulsivo a se livrar de um hábito problemático. O AA o coloca dentro de uma comunidade que, de forma global, reordena sua vida. O AA lhe fornece um novo entendimento de si mesmo e novas motivações para agir - de fato, uma nova identidade" (:149). Antze diz ainda que o grupo acaba por dar suporte social e psicológico aos dependentes: "o grupo fornece uma identidade e um senso de propósito aos membros, ele os educa em como ter uma conduta geral de vida, e os liga a uma comunidade" (:151). Este sentido de pertencimento a uma comunidade é o que os auxilia a vencer o egoísmo, indicado por Antze como a raiz do problema do alcoólatra, exatamente porque, ao não conseguir do mundo o que deseja, o alcoólatra se vê imerso em sentimentos de raiva, ressentimento, depressão, medo e autopiedade, sentimentos estes que o induzem a beber. Laudet et al. (2002) corroboram este entendimento da importância do grupo no processo de recuperação, mas a partir de uma outra perspectiva. Segundo estes autores, o suporte da família e dos amigos é fundamental para a manutenção da abstinência.

Como coloca claramente o Escritório das Nações Unidas para a Droga e o Crime (em conjunto com a Organização Mundial da Saúde — ver UNODC/WHO 2008):

a dependência de drogas é considerada uma desordem da saúde de ordem multifatorial [...] Recentemente, o modelo biopsicossocial tem reconhecido a dependência de drogas como um problema multifacetado, requerendo a experiência de várias disciplinas. Uma aproximação multidisciplinar a partir das ciências da saúde pode ser aplicada à pesquisa, prevenção e tratamento. Durante as últimas décadas, a dependência de drogas tem sido considerada, de acordo com as diferentes crenças ou pontos de vista ideológicos, como: somente um problema social, somente uma questão educacional ou espiritual, somente um comportamento culposo a ser punido, somente como um problema farmacológico. A noção de que a dependência pudesse ser considerada uma doença "autoadquirida", baseada na escolha livre e pessoal da primeira experimentação com drogas ilícitas, tem contribuído para o estigma e a discriminação associada com a dependência de drogas. Contudo, evidências científicas indicam que o desenvolvimento da doença é o resultado de uma interação complexa e multifatorial entre a exposição repetida às drogas e fatores biológicos e ambientais (:1). 
Esta perspectiva demonstra que a dependência deve ser entendida não apenas como um problema químico, psicológico ou moral, mas sim como um problema essencialmente social e cultural - algo que já foi apontado por diversos autores, como, por exemplo, Alexander (2008), Langdon (2004) e Room (1985) - mas ela assume também, de acordo com a perspectiva dos centros pesquisados, um aspecto "espiritual". A questão que se coloca então é: será que este "aspecto espiritual" serve simplesmente como mais uma ferramenta (aparentemente adequada) para uma ressocialização do dependente (ver Sanchez \& Nappo 2007; Panzini \& Bandeira 2007; Heath 1987)? Ou será que, além disso, haveria um "algo mais" proporcionado pela experiência de transcendência que reorientaria toda a vida do dependente?

Schneider (2010), por exemplo, coloca que é exatamente tal vivência da espiritualidade promovida pelo chá que leva à "transformação" do dependente, trazendo-o de volta a uma vida social que estava sendo negligenciada. Alpert \& Lostof (2007) também indicam que a recuperação da dependência é entendida como um acontecimento espiritual, segundo a visão de pessoas que passaram por um tratamento com iboga.

Além disso, se a "adicção" e a "dependência" foram "descobertas" no século XIX, estes são problemas relativamente recentes, provavelmente resultantes do estilo de vida que temos em nossa sociedade. Será então que a dependência, mais que um problema, não seria um sinal, um efeito (colateral) de nosso estilo de vida? ${ }^{15}$ É importante frisar que o "sinal" seria a dependência, e não a busca de estados especiais de percepção — esta busca é tão antiga quanto o ser humano (ver Winkelman 2000). Vivemos em uma sociedade fortemente "monofásica" (Lauglhin et al. 1992) ou "enteofóbica" (no sentido de que tem fobia aos chamados "enteógenos" ou substâncias psicoativas - ver Blainey, 2010), onde a única realidade válida é aquela com que se tem contato quando se está acordado, sem que se tenha ingerido nada que altere o modo como percebemos o mundo. A dependência seria então uma reação de alguns (ou muitos) indivíduos "enteofílicos" e que não têm o devido espaço para dar vazão à sua afinidade. Os psicoativos são uma fonte de acesso a tais estados "multifásicos", uma porta para a transcendência, transcendência esta que foi indicada por vários de meus informantes como tendo sido buscada, de forma equivocada, através do uso de drogas e do álcool.

Estas são questões complexas que não podem ser respondidas em um único texto ou mesmo no decorrer de uma pesquisa. Mas que devem ser levantadas, expandindo os horizontes da pesquisa em andamento e justificando a realização de uma revisão bibliográfica mais ampla envolvendo este tema. 
Marcelo S. Mercante é professor visitante. Departamento de Antropologia, UFMG. E-mail: <marcelo_mercante@yahoo.com>

\section{Notas}

* Agradeço à Fapesp pela bolsa que permitiu a pesquisa que resultou neste artigo e ao prof. José Guilherme Magnani pela orientação durante o pós-doutorado. Agradeço ainda a Eduardo Schemberg e Bia Labate pela leitura atenta e os comentários.

${ }^{1}$ Este projeto de pesquisa foi desenvolvido ao longo de três anos de pós-doutoramento no Departamento de Antropologia da Universidade de São Paulo, com bolsa da Fapesp, entre os anos de 2009 e 2012, sob o título "O Uso Terapêutico e Ritualístico da Ayahuasca no Tratamento de Dependência Química e Alcoolismo". O objetivo principal foi saber como trabalhavam estes centros e o papel das experiências com ayahuasca no processo de recuperação. Importante notar que "recuperação", neste texto, assume a perspectiva que os centros de tratamento pesquisados dão, ou seja, está recuperado um paciente que não faz uso de nenhuma substância psicoativa - exceto, é claro, a ayahuasca.

${ }^{2}$ Ver por exemplo a definição do American College of Physicians (1985:405): "dependência química se refere à necessidade física ou psíquica de uma substância química e envolve o alcoolismo e a dependência de drogas". Para uma revisão bastante ampla do termo dependency, ver Alexander (2008).

${ }^{3}$ Este artigo, contudo, está centrado na questão da dependência química.

${ }^{4}$ Ver Labate e Araújo (2002) para mais detalhes sobre cada uma destas religiões. De forma sucinta, em 1930 o seringueiro Raimundo Irineu Serra, negro oriundo do Maranhão, após uma visão da Virgem da Conceição inicia a formação de um grupo do qual surgirá o Santo Daime; em 1945 é fundada a Barquinha (ver Mercante 2012), com Daniel Pereira de Mattos. Tanto Barquinha quanto Santo Daime tiveram seu começo em Rio Branco, Acre. Em 1960 surge a União do Vegetal, com José Gabriel da Costa, em Porto Velho. As três religiões estão baseadas em um sincretismo bastante próprio do cristianismo, são religiões de origem afro-brasileira e práticas indígenas.

${ }^{5}$ O GMT foi um Grupo Multidisciplinar de Trabalho instituído pelo Conad (Conselho Nacional de Políticas sobre Drogas) em 2004, formado por profissionais de diversas áreas (médicos, psicólogos, antropólogos) e representantes das igrejas ayahuasqueiras, para 
elaborar um documento que fornecesse diretrizes normativas para o uso da ayahuasca no Brasil. Tal documento ficou pronto em 2006, e foi publicado, através da Resolução 01 de 25 de janeiro de 2010, pelo Gabinete de Segurança Institucional do Conad.

6 "Pacientes" e "cuidadores" são termos éticos. Devido ao caráter multilocal da pesquisa, sinto-me impossibilitado de utilizar um termo êmico. Em Takiwasi há os "terapeutas" e os "pacientes". No Caminho de Luz temos os "monitores" e o "Mestre", de um lado, e os "internos", de outro. No Céu Sagrado há apenas os dependentes, assim como no Céu da Nova Vida. Da mesma forma, muitos "cuidadores" já foram pacientes e as entrevistas com eles revelaram esta condição, mais até do que a de "cuidador".

${ }^{7}$ Nos Estados Unidos, já em 1791, Benjamim Rush (An enquiry into the effects of spiritous liquors upon the human body and their influences upon the happines of society) dizia que a embriaguez crônica era tanto uma doença quanto um transtorno da vontade. Em 1891, Carl Von Bruhl-Cramer colocou que a embriaguez resultava de "uma doença do sistema nervoso, que produzia um desejo irresistível pelo álcool" (Berridge 1994:17), e chamou tal doença de "dipsomania".

${ }^{8}$ Chwelos et al. 1959; Jensen 1962; Ross MacLean et al. 1961; Smith 1958.

${ }^{9}$ Ver Halpern (2007) para uma boa revisão da literatura sobre a posterior proibição do uso do LSD neste tipo de tratamento.

${ }^{10}$ Ver também Dobkin de Rios et al. (2002), Fernandez (2003), Halpern (1996, 2007), Winkelman (2001) para uma revisão geral. Labate et al. (2010) trata de uma revisão bibliográfica do uso da ayahuasca como instrumento terapêutico. O livro Psychelic medicine (Wilkelman \& Roberts 2007), com dois volumes, cobre de forma ampla o uso de psicoativos no tratamento de diversos problemas, incluindo dependência.

${ }^{11}$ Curiosamente, uma mistura de sementes de aniz, nabo, sal e mel em água morna era utilizada há mil anos atrás pelos persas para induzir vômito e diminuir a toxidade do ópio (Heggenhougen 1984). Heggenhougen também indica que em um mosteiro budista na Tailândia a mesma técnica é utilizada hoje em dia. Gomes (2011) fez um relato sobre o trabalho da Unidade de Resgate Flor das Águas Padrinho Sebastião, liderada por Walter De Lucca, onde se utilizava ayahuasca para auxiliar moradores de rua. No processo terapêutico adotado, também se faziam purgas com Yawar Panga, uma vez que Walter havia passado por Takiwasi. Mas o interessante é que os dependentes auxiliados por De Lucca também pediam, com frequência, para fazer purgas.

${ }^{12}$ Esta prática foi modificada. Atualmente, o paciente bebe o chá apenas uma vez por dia, nas reuniões, e somente se assim o desejar.

${ }^{13}$ Mistura de pasta base de cocaína com bicarbonato de sódio, sendo esta a forma mais barata de uso da cocaína que existe no mercado. O crack se encontra na forma de "pedras", que são fumadas pelos usuários.

${ }^{14}$ Pasta base de cocaína. No Acre, o uso mais intenso é da "mela", e não do crack. 
${ }^{15}$ Heath (1987), citando Bales (1946), diz que havia menos problemas no uso de álcool entre judeus, nos Estados Unidos - que possuem um estilo de vida no qual a coesão do grupo é muito importante, havendo um aprendizado caseiro de consumo de bebidas em um contexto ritual - do que entre descendentes de irlandeses (estes sim, com significativo índice de problemas no consumo de álcool), aliado a um alto índice de frustração econômica.

\section{Referências bibliográficas}

ALEXANDER, Bruce. K. 2008. The globalization of addiction. A study in poverty of the spirit. Oxford: Oxford University Press.

ALPERT, Keneth R. \& LOTSOF, Howard S. 2007. "The use of ibogaine in the treatment of addictions". In: Michael Winkelman\& Tom Roberts (eds.), Psychedelic medicine. New evidences for hallucinogenic substances as treatments. Vol. II. Westport:Praeger.pp. 43-65.

AMERICAN COLLEGE OF PHYSICIANS (Health and Public Policy Committee). 1985. "Chemical dependence". Annals of Internal Medicine, 102(3):405-408.

ANTZE, Paul. 1991. "Symbolic action in Alcoholics Anonymous". In: Mary Douglas (ed.), Constructive drinking: perspectives on drink from anthropology. Cambridge: Cambridge University Press. pp. 149-181.

BABOR, Thomas F. 1994. "Controvérsias sociais, científicas e médicas na definição de dependência do álcool e das drogas". In: G. Edwards \& M. Lader (eds.), A natureza da dependência de drogas. Porto Alegre: Artes Médicas. pp. 35-60.

BALES, R. F. 1946. "Cultural differences in rates of alcoholism".Quartely Journal of Studies of Alcohol, 6:480-499.

BAKER, John R. 2002. "Hallucinogens and redemption: alcohol abuse and the ethos of power in Navajo hea- ling". Medical Anthropology Quarterly, 14(4):521-542.

BECKER, Howard S. 1967. "History, culture and subjective experience: an exploration of the social bases of drug-induced experiences". Jounal of Health and Social Behavior, 8(3):163-176.

BERRIDGE, Virginia. 1994. "Dependência: história dos conceitos e teorias". In: G. Edwards \& M. Lader (eds.) A natureza da dependência de drogas. Porto Alegre: Artes Médicas. pp. 13-34. BLAINEY, Marc. 2010. "An ethnometaphysics of consciousness: suggested adjustments in SAC quest to reroute the main(stream)". Anthropology of Consciousness, 21(2):113-38.

BRISSAC, Sérgio. 1999.A estrela do norte iluminando até o sul. Uma etnografia da União do Vegetal em um contexto urbano. Dissertação de Mestrado, PPGAS/MuseuNacional/ UFRJ.

BOURGOIS, Philippe. 2000."Disciplining addictions: the bio-politics of methadone and heroin in the United States". Culture, Medicine and Psychiatry, 24:165-195.

BURNS, John E. 1995. O Caminho dos Doze Passos. Tratamento de dependência de álcool e outras drogas. São Paulo: Edições Loyola.

BUSTOS, Susana. 2008. The healing power of the icaros: a phenomenological study of ayahuasca experiences. Tese 
de doutorado, California Institute of Integral Studies.

CAIN, Carole. 1991. "Personal stories: identity acquisition and self-understanding in Alcoholics Anonymous". Ethos, 19(2):210-253.

CALABRESE, J.D. 1997. "Spiritual healing and human development in the Native American Church: toward a cultural psychiatry of peyote".The Psychoanalytic Review, 84(2):237-255.

CAMPOS, Edemilson. A. 2005."Contágio, doença e evitação em uma associação de ex-bebedores: o caso dos Alcoólicos Anônimos". Revista de Antropologia, 48(1):315-361.

CARNEIRO, Henrique. 2008. "Autonomia ou heteronomia nos estados alterados de consciência".In: Beatriz C. Labate et al. (orgs.), Drogas e cultura: novas perspectivas. Salvador: Edufba. pp. 65-90.

CHWELOS, N.; BLEWETT, D. B.; SMITH, C. M. \& HOFFER, A. 1959. “Use of $d$ lysergic acid diethylamide in the treatment of alcoholism".Quarterly Journal of Studies of Alcohol, 20:577-590.

CEMIN, Arneide B.; MEDEIRO, E. C. \& ARAÚJO, E.D. 2000."A ayahuasca como terapêutica para o uso de drogas (o imaginário do uso e da cura)". Labirinto: Revista Eletrônica do Centro de Estudos do Imaginário. Disponível em: http://www.cei.unir.br/artigo22. html. Acesso em: 22/11/2006.

CSORDAS, Thomas. J. 1994. The sacred self. A cultural phenomenology of charismatic healing. Berkeley: University of California Press.

DOBKIN DE RIOS, Marlene; GROB, Charles S. \& BAKER, John R. 2002."Hallucinogens and redemption".Journal of Psychoactive Drugs, 34:239-248.

EDITORS, THE. 1963. "The treatment of alcoholism with psychedelic drugs". The Psychedelic Review, 1(2):205-207.

FERNANDEZ, Xavier. 2003. "Estados modificados de consciencia con enteógenos en el tratamiento de las drogodependencias". Revista de Etnopsicología, 2:33-45.

GARRITY, J. F. 2000. "Jesus, peyote and the holy people: alcohol abuse and the ethos of power in Navajo healing". Medical Anthropology Quarterly, 14(4):521-542.

GIOVE, Rosa. 2000. La liana de los muertos al rescate de la vida. Medicina tradicional amazónica en el tratamiento de las toxicomanias. Siete anõs de experiencia del Centro Takiwasi. Tarapoto: Takiwasi/DEVIDA.

GOMES, Bruno R. 2011.O sentido do ritual da ayahuasca em trabalho voltado ao tratamento e recuperação da população em situação de rua em São Paulo. Dissertação de mestrado, Faculdade de Saúde Pública, USP.

GMT (Grupo Multidisciplinar de Trabalho Ayahuasca). 2006.Relatório final. Brasília:Conad. Disponível em: http://obid.senad.gov.br/OBID/Diversos/salvarlocal.jsp?id=18276 Acesso em: 13/11/2007.

HALPERN, John H. 1996. "The use of hallucinogens in the treatment of addiction".Addiction Research, 4(2):177-189. . 2007. "Hallucinogens in the treatment of alcoholism and other addictions". In: Michael Winkelman \& Tom Roberts (eds.), Psychedelic medicine. New evidence for hallucinogens substances as treatments. Vol. I. Westport: Praeger Perspectives. pp. 1-14.

HALPERN, John H. et al. 2005. "Psychological and cognitive effects of long-term peyote use among Native Americans". Biological Psychiatry, 58:624-631.

HARRINGTON, Nora. 2008. The psychology of plants. An ethnography of patient-provider relationship at the Takiwasi Center for rehabilitation. Tese de doutorado, School of Social Sciences, Hampshire College. 
HEATH, Dwight B. 1987."Anthropology and alcohol studies: current issues". Annual Review of Anthropology, 16: 99-120.

HEGGENHOUGEN, H.K. 1984."Traditional medicine and the treatment of drug addicts: three examples from Southeast Asia". Medical Anthropology Quarterly, 16(1):3-7.

HENMAN, Anthony R. 2008. "A coca como planta mestra: reforma e nova ética". In: Beatriz C. Labateet al. (orgs.), Drogas e cultura: novas perspectivas. Salvador: Edufba. pp. 369-380.

JENSEN, Sven E. 1962. "A treatmentprogram for alcoholics in a mental hospital".Quarterly Journal of Studies of Alcohol, 23:315-320.

KOENIG, Harold G. 2007. "Religião, espiritualidade e psiquiatria: uma nova era na atenção à saúde mental". Revista de Psiquiatria Clínica, 34 (supl. 1):5-7.

LABATE, Beatriz C. 2004.A reinvenção do uso da ayahuasca nos centros urbanos. Campinas: Mercado das Letras. - \& ARAÚJO, Wladimir S. 2002. O uso ritual da ayahuasca. Campinas: Mercado das Letras.

. et al. 2010. "The treatment and handling of substance dependence with ayahuasca: reflections on current and future research".In: Beatriz C. Labate \& Edward MacRae (eds.), Ayahausca, ritual and religion in Brazil. London: Equinox.pp. 205-228.

LABIGALINI JR., Eliseu. 1998.O uso de ayahuasca em um contexto religioso por ex-dependentes de álcool - um estudo qualitativo.Dissertação de mestrado, Escola Paulista de Medicina, Unifesp. . \& RODRIGUES, L. R. 1997. "O uso 'terapêutico' de Cannabis por dependentes químicos de crack no Brasil". PsychiatryOnLineBrazil, 2. Disponível em: http://www.priory.com/psych/eliseu.htm. Acesso em 23/09/2006.
LANGDON, Esther Jean M. 2004. "L'abus d'alcool chez les peoples indigènes du Brésil: une évaluation comparative". Drogues, Santé, et Societé, 4(1):15-52.

LAUDET, Alexandre B.; SAVAGE, Robert \& MAHMOOD, Daneyal, 2002."Pathways to long-term recovery: a preliminary investigation". Journal of Psychoactive Drugs, 34(3):305-311.

LAUGHLIN, C.; MCMANUS, J. \& D'AQUILI, E. 1992. Brain symbol and experience toward a neurophenomenology of consciousness. New York: Columbia University Press.

LENAERTS, Marc. 2006. "Substances, relationships and the omnipresence of the body: an overview of Ashéninka ethnomedicine (Western Amazonia)". Journal of Ethnobiology and Ethnomedicine, 2:49. Disponível em: http://www.ethnobiomed.com/content/2/1/49. Acesso em: 20/09/2009.

LENDE, Daniel H. 2005. "Wanting and drug use: a biocultural approach to the analysis of addiction". Ethos, 33(1):100-124.

LUNA, L. E. 1986. Vegetalismo: shamanism among the mestizo population of the Peruvian Amazon. Estocolmo: Almqvist \& Wiksell International.

MABIT, Jacques. 2002."Using indigenous medicinal knowledge to treat drug addiction". MAPS, Bulletin of the Multidisciplinary Association for Psychedelic Studies, 12(2):25-32. -2006. Ayahuasca helps cure drug addiction. Disponível em: www.takiwasi.com/ docs/eng/Ayahuasca_helps_cure_drug_ addiction.doc. Acesso em: 25/03/2008. . 2007. "Ayahuasca in the treatment of addictions". In: Michael J. Winkelman \& Tom B. Roberts(eds.),Psychedelic medicine. New evidence for hallucinogenic substances astreatments. Vol. II. Westport: Praeger Perspectives. pp. 87-106.

MABIT, Jacques; GIOVE, Rosa \& VEGA, Joaquin. 1996."Takiwasi: the use of 
Amazonian shamanism torehabilitate drug addicts". In: Michael J. Winkelman \& W. Andritziky (eds.), Yearbook of cross-cultural medicine and psychotherapy 1995. Theme issue: sacred plants, consciousness, and healing. Cross-cultural and interdisciplinary perspectives. Berlin: Verlag fur Wissenschaft und Bildung. pp. 257-285.

MAGNANI, José G. C. 1999. Mystica urbe. Um estudo antropológico sobre o circuito neo-esotérico na metrópole. São Paulo: Studio Nobel.

MARRAS, Stelio. 2008. "Do natural ao social: as substâncias em meio estável". In: Beatriz C. Labateet al. (orgs.), Drogas e cultura: novas perspectivas. Salvador: Edufba. pp. 155-186.

MCKENNA, Dennis. 2004. "Clinical investigations of the therapeutic potential of ayahuasca: rationale and regulatory challenges". Pharmacology \& Therapeutics, 102:111-129.

MERCANTE, Marcelo S. 2002."Ecletismo, caridade e cura na Barquinha da Madrinha Chica". Humanitas, 8(2):47-60. -2004. Miração and healing: a study concerning spontaneous mental imagery and healing process. Tucson: Toward a Science of Consciousness Conference. - 2006a. The objectivity of spontaneous mental imagery: the spiritual space of a Brazilian-Amazonian religion experienced by sacramental users of ayahuasca. Tucson: Toward a Science of Consciousness Conference.

. 2006b. Images of healing: spontaneous mental imagery and healing process of the Barquinha, a Brazilian ayahuasca religious system. Tese de doutorado, Saybrook Graduate School and Research Center.

. 2006c "The objectivity of spiritual experiences: spontaneous mental imagery and the spiritual space". Revista Eletrônica Informação e Cognição, 5:78-98. Disponível em: http://www. portalppgci.marilia.unesp.br/reic/include/getdoc.php?id $=144 \&$ article $=37$ $\&$ mode $=$ pdf. Acesso em 30/03/2007. . 2009. "Ayahuasca, dependência química e alcoolismo". Ponto.Urbe, 5:1-23. Disponível em: http://www.pontourbe. net/edicao5-artigos/37-ayahuascadependencia-quimica-e-alcoolismo. Acesso em: 04/10/2011.

2010. Images of healing: spontaneous mental imagery and healing process of the Barquinha, a Brazilian ayahuasca religious system. Saarbrucken: Lambert AcademicPublishingHouse.

- 2012. Imagens de cura. Ayahuasca, imaginação, saúde e doença na Barquinha. Rio de Janeiro: Editora Fiocruz.

MOIR, John. 1998 "Shamanism, traditional medicine and drug dependency in the Peruvian upper Amazon". Lila. Disponível em: http://www.lila.info/ document_view.phtml? document_ $\mathrm{id}=15$. Acesso em:15/09/2005.

MOURE, Walter G. 2005.Saudades da cura: estudo exploratório de terapêuticas de tradição indígena da Amazônia peruana. Tese de doutorado, Instituto de Psicologia, USP.

PANZINI, Raquel G. \& BANDEIRA, Denise R. 2007. "Coping (enfrentamento) religioso/espiritual". Revista de Psiquiatria Clínica, 34(supl.1):126-135.

RICCIARDI, Gabriela S. 2008. O uso da ayahuasca e a experiência de transformação, alívio e cura na União do Vegetal (UDV). Dissertação de mestrado, PPGAS-UFBA.

ROOM, Robin. 1985. "Dependence and society". Britsh Journal of Addiction, 80(2):133-139.

ROSS MACLEAN, J.; MACDONALD, D. C.; BYRNE, U. \& HUBBARD, A. M. 1961. "The use of LSD-25 in the treatment of alcoholism and other psychiatric problems". Quarterly Journal of Studies of Alcohol, 22:34-45. 
SALDAÑA, Alvaro C. \& GUIRRIMÁN, Mónica O. 2008. "Aproximaciones antropológicas al modelo terapéutico del Centro Takiwasi". Tarapoto: Universidad Católica de Temuco \& Takiwasi (manuscrito). SANCHEZ, Zila M. \& NAPPO, Solange A. 2007. "A religiosidade, a espiritualidade e o consumo de drogas". Revista de Psiquiatria Clínica, 34(supl. 1):73-81.

SANTOS, Raphael G.; MORAES, Célia C. \& HOLANDA, Adriano. 2006. "Ayahuasca e redução do uso abusivo de psicoativos: eficácia terapêutica?".Psicologia: Teoria e Pesquisa, 22(3):363-70.

SCHNEIDER, Jaqueline. 2010. Dos fios quotidianos à trama terapêutica: subjetividade, uso de drogas e experiência. Dissertação de mestrado, PPGAS-UFSC.

SHANON, Benny. 2002. The antipodes of the mind: charting the phenomenology of the ayahyuasca experience. Cambridge: Oxford University Press.

SIEBER, Claire L. 2007. Enseñanzas y mareaciones: exploring intercultural health through experience and interaction with healers and plant teachers in San Martín, Peru.Dissertação de mestrado, Departamento de Antropologia, Universidade de Victoria.

SIMMEL, Georg. 2010a. "O problema da situação religiosa". In: Religião.vol. 1. São Paulo: Olho D'Água. pp. 9-20. . 2010b. "A religião". In: Religião.vol. 1. São Paulo: Olho D'Água. pp. 21-90.

_ 2011. "A religião e os opostos da vida". In: Religião.vol. 2. São Paulo: Olho D'Água. pp. 31-38.

SIMÕES, Julio A. 2008. "Prefácio". In: Beatriz C. Labate et al.(orgs.),Drogas e cultura: novas perspectivas. Salvador: Edufba. pp. 13-22.

SMITH, Colin M. 1958. "A new adjunct to the treatment of alcoholism: the hallucinogenic drugs". Quarterly Journal of Studies of Alcohol, 19:406-417.
UNODC/WHO (United Nations Office on Drugs and Crime - World Health Organization). 2008. Principles of drug dependence treatment. Discussion paper. Disponível em: http://www. unodc.org/documents/drug-treatment/UNODC-WHO-Principles-ofDrug-Dependence-Treatment-March08.pdf. Acesso em: 22/08/2011.

VARGAS, Eduardo V. 2008. "Fármacos e outros objetos sociotécnicos: notas para uma genealogia das drogas". In: Beatriz C. Labate et al. (orgs.), Drogas e cultura: novas perspectivas. Salvador: Edufba. pp. 41-64.

WINKELMAN, Michael J. 1996. "Psychointegrator plants: their roles in human culture, consciousness and health". In: Michael J. Winkelman \& W. Andritziky (eds.), Yearbook of cross-cultural medicine and psychotherapy 1995. Theme issue: sacred plants,consciousness, and healing. Cross-cultural and interdisciplinary perspectives. Berlin: Verlag fur Wissenschaft und Bildung. pp. 9-54. -2000. Shamanism: the neural ecology of consciousness and healing. Westport: Bergin \& Garvey. . 2001. "Alternative and traditional medicine approaches for substance abuse programs: a shamanic perspective". International Journal of Drug Policy, 12:337-351.

WINKELMAN, Michael J. \& ROBETS, Tom (eds.). 2007. Psychedelic medicine. New evidence for hallucinogenic substances as treatments. Westport: Praeger Publishers.

YENSEN, Richard \& DRYER, Donna. 1999. "Addiction, despair, and the soul: successful psychedelic psychotherapy, a case study". Societat d'Etnopsicologia i Estudis Cognitius. Disponível em: http://www.etnopsico.org/index.php ?option $=$ content $\&$ task $=$ view $\& i d=61$. Acesso em: 25/10/2006. 


\section{Resumo}

A ayahuasca é uma bebida psicoativa utilizada por diversos grupos indígenas por toda a Amazônia, assim como por xamãs mestiços (chamados "vegetalistas") e por religiões e grupos independentes no Brasil. Desde a década de 1990 esta bebida vem sendo empregada no tratamento da dependência. Existem atualmente alguns centros espalhados pela América do Sul que realizam este tipo de tratamento. Realizei trabalho de campo em quatro deles, um no Peru e três no Brasil. Neste artigo faço uma pequena descrição etnográfica destes centros e teço algumas considerações sobre o papel da experiência durante o efeito do chá no processo de recuperação da dependência e também da possibilidade deste tipo de tratamento não ser uma mera terapia de substituição.

Palavras-chave Dependência, Drogas, Ayahuasca, Imaginação, Experiência.

\section{Abstract}

Ayahuasca is a psychoactive drink used by many Indigenous groups throughout Amazonia, as well as by mestizo shamans (known as "vegetalistas"), religions and independent groups in Brazil. Since the 1990's the drink has been used to treat dependency. At present, there are a few centres in South America that carry out this type of treatment. I carried out fieldwork in four of them, one in Peru and three in Brazil. In this article I present a short ethnographic description of these centres and offer some considerations about the role of experience during the effects of the tea in the process of recovery from dependency. I also consider the possibility that this type of treatment is not merely a substitution therapy.

Key words Dependency, Drugs, Ayahuasca, Imagination, Experience. 